Memoirenliteratur und den Intellektuellen. In seinem Beitrag Die verhinderten Hochverräter problematisierte er nicht zuletzt das vom ehemaligen Mitarbeiter des Auswärtigen Amtes in der Zeit des Naziregimes, Ernst von Weizsäcker, verfasste Buch Erinnerungen. ${ }^{452}$

De Mendelssohn beleuchtete intensiv das Verhältnis von Intellektuellen zum NSSystem. Sein Beitrag Gegenstrahlungen, in dem er sich kritisch mit Ernst Jünger auseinandersetzte, ${ }^{453}$ mündete inhaltlich in das Kapitel »Über die Linie des Geringsten Widerstandes. Versuch über Ernst Jünger « seines 1953 erschienenen Buches Der Geist in der Despotie. Versuche über die moralischen Möglichkeiten des Intellektuellen in der totalitären Gesellschaft ${ }^{454}$. Hierbei ging er der Frage der Rolle des Intellektuellen, seinen moralischen Möglichkeiten und moralischen Verpflichtungen in einer »totalitären Despotie« nach, und zwar anhand von Knut Hamsun, Jean Giono, Gottfried Benn ${ }^{455}$ und dem bereits genannten Ernst Jünger. Das Kapitel über Hamsun erschien in einer stark gekürzten Fassung im Monat. ${ }^{456}$ Auf dem Berliner »Kongreß für kulturelle Freiheit« im Juni 1950 betonte de Mendelssohn in seinem Vortrag Die Versuchung des Intellektuellen die »magische Anziehungskraft« geschlossener, totalitärer Denksysteme auf Intellektuelle. $^{457}$

\title{
4.10 Herbert Lüthy
}

Mit knapp 70 Veröffentlichungen zählte der Historiker, Essayist und freie Journalist Herbert Lüthy zu den zweifelsohne populärsten und einflussreichsten Autoren der Zeitschrift Der Monat. Parallel veröffentlichte er zahlreiche Beiträge in der französischen »Partnerzeitschrift« Preuves, sodass er zu einem »der wichtigsten Verbindungsglieder dieses europäischen Zeitschriftennetzwerkes « zählte. ${ }^{458}$

Lüthy wurde in Basel als Sohn eines Missionars am 15. Januar 1918 geboren und besuchte bis 1938 die Schulen in Glarus und St. Gallen. Während des Zweiten Weltkrieges studierte Lüthy in Zürich Geschichte, französische Sprache und Literatur und schloss das Studium 1943 mit einer Dissertation zum Thema Die Tätigkeit der Schweizer Kaufleute und Gewerbetreibenden in Frankreich unter Ludwig XIV. und der Regentschaft ab. ${ }^{459}$ Nach Kriegsende lebte Lüthy bis 1958 in Paris und arbeitete in diesen Jahren nicht nur

452 Die Verhinderten Hochverräter. Wege und Irrwege neuerer deutscher Memoirenliteratur, in: Der Monat 3 (1951), H. 29, S. 495-509 (Sammelrezension). Auf diesen Rezensionsaufsatz gehe ich in Kap. IV.1.7 ausführlich ein.

453 Gegenstrahlungen. Ein Tagebuch zu Ernst ]üngers Tagebuch, in: Der Monat 2 (1949), H. 14, S. 149-174 (Rezension).

454 Der Geist in der Despotie. Versuche über die moralischen Möglichkeiten des Intellektuellen in der totalitären Cesellschaft; siehe hierzu Bondy, Rebellen als Musterschüler.

455 Auf meine Frage, warum der Beitrag über Knut Hamsun und nicht der über Gottfried Benn im Monat veröffentlicht wurde, obwohl dieser in der Zeitschrift angekündigt wurde, sagte der Herausgeber Lasky in einem Gespräch mit dem Verfasser im November 2001 in Berlin, dass der Redaktion dieser Beitrag »politisch zu brisant« erschien.

456 Knut Hamsun. Erleuchtung und Verblendung des Zerrissenen, in: Der Monat 5 (1953), H. 55, S. 50-70.

457 Die Versuchung des Intellektuellen, in: Der Monat 2 (1950), H. 22/23, S. 384-386.

458 So die Einschätzung von François Bondy (zit. n. Ackermann, Sündenfall der Intellektuellen, S. 81).

459 So Lüthy in einem Gespräch mit dem Verfasser im Juli 2001 in Basel. 
für die Zeitschriften Monat und Preuves, sondern auch für den Encounter sowie als Auslandskorrespondent für die Tageszeitung Die Tat. In dieser Zeit gab er einerseits einen Band mit Essays von Michel de Montaigne ${ }^{460}$ heraus und verfasste andererseits das Buch Frankreichs Uhren gehen anders ${ }^{461}$, das die »innen- und aussenpolitischen Ausweglosigkeiten « (Urs Bitterli) Frankreichs in den ersten Jahren der Vierten Republik zum Kernthema hatte und mit dem er einem breiten Publikum bekannt wurde, sowie in französischer Sprache seine zweibändige Habilitationsschrift, die finanzgeschichtliche Studie La Banque protestante en France. ${ }^{462}$ Ab 1958 lehrte Lüthy Geschichte an der Eidgenössischen Technischen Hochschule in Zürich und von 1971 bis 1980 an der Universität in Basel. Nach dem 1989 herausgegebenen kleinen Band Tugend und Menschenrechte. Zur Topologie politischer Begriffssysteme ${ }^{463}$ erschien zwei Jahre später sein Buch Wo liegt Europa? Zehn Versuche zu den Umtrieben des Zeitgeistes, das unter anderem einige frühere Aufsätze aus dem Monat enthielt. ${ }^{464}$ Lüthy, der den Ruf besaß, der vielleicht »beste Historiker« (Georg Kreis) der Schweizer Nachkriegszeit ${ }^{465}$ gewesen zu sein, lebte bis zu seinem Tod im Alter von 84 Jahren am 16. November 2002 mit seiner Frau in Basel. ${ }^{466}$

Als politisch interessierter Zeitzeuge beschäftigte sich Lüthy in den 1940er-Jahren mit den weltgeschichtlichen Ereignissen des durch den deutschen Nationalsozialismus entfesselten Angriffskrieges auf die Sowjetunion. Seine Kleine Wochenschau unterrichtete die Leser in der Samstagsausgabe des St. Galler Tageblatt von September 1942 bis Dezember 1943 über »einen ganz bestimmten Abschnitt des zweiten Weltkrieges, jene Zeit von den sstehenden Schlachten von Stalingrad und El Alamein bis zu den Konferenzen um Teheran, in der die Entscheidung des Krieges schon mit Händen greifbar und doch, durch keine Evidenz unleugbarer Umwälzungen erwiesen, noch in unendlicher Ferne schien [...], in der alle Uhren falsch gingen und viel von >zwölf Uhr die Rede war, aber niemand wußte, wie spät es sei - kurz: die Zeit des Nervenkrieges ${ }^{467}$. Vor dem Hintergrund der Thematisierung der Bedeutung des NSDAP-

460 Michel de Montaigne, Essais. Auswahl und Übersetzung von Herbert Lüthy, Zürich 1953.

461 Herbert Lüthy, Frankreichs Uhren gehen anders, Zürich u. a. 1954.

462 Ders., La banque protestante en France de la révocation de l'Edit de Nantes à la Révolution. 2 Bde., Dispersion et regroupement (1685-1730), Bd. 1, Paris 1959; De la banque aux finances (1730-1794), Bd. 2, Paris 1961.

463 Ders., Tugend und Menschenrechte. Zur Topologie politischer Begriffssysteme, Zürich 1989.

464 Ders., Wo liegt Europa? Zehn Versuche zu den Umtrieben des Zeitgeistes, Zürich 1991. Der Band enthielt folgende frühere Veröffentlichungen aus dem Monat: »Als Zeus Europen liebgewann. [Die >Integration< und die `Konförderation«]«; »Montaigne oder die Wahrhaftigkeit«; »Arte povera«; »Wozu Geschichte« sowie »1914. Das Ende einer Welt«.

465 Zur politisch-historischen Entwicklung der Schweiz im Allgemeinen und im 20. Jahrhundert im Besonderen vgl. ders., Die Schweiz als Antithese, Zürich 1969.

466 Kurz vor dem Tod konnte Lüthy noch erleben, wie die beiden ersten Bände einer Werkausgabe erschienen, die im Jahre 2005 mit der Veröffentlichung des siebten Bandes abgeschlossen wurde. Vgl. Herbert Lüthy, Werkausgabe. Edition von Irene Riesen und Urs Bitterli. 7 Bde., Zürich 2002-2005.

467 Ders., Fünf Minuten vor zwölf. Feldzüge und Konferenzen von Stalingrad bis Teheran, St. Gallen 1944, S. 5 f. Bei diesem Tagebuch der Eindrücke und Reflexionen eines Zeitgenossen überrascht bei der heutigen Lektüre die große Genauigkeit und Sensibilität des Zeitzeugen Lüthy für historische Ereignisse fernab von den eigentlichen »stehenden Schlachten«. So ging er beispielsweise in den Berichten vom 12. September 1942 auf die Verfolgungen und Deportationen der französischen Juden der deutschen Besatzungsbehörde und der Vichyregierung unter Marshall Pétain ein sowie auf Pro- 
Parteiprogramms und seiner Feststellung, dass die nationalsozialistische Bewegung insbesondere von der »verzweifelten Begeisterung des deutschen Mittelstandes zur Macht getragen wurde ${ }^{468}$ kam Lüthy im Kontext der Auseinandersetzung mit dem deutschen Kreuzzug gegen den Bolschewismus ${ }^{469}$ beispielsweise auch auf die $»$ nationale Unterdrückung, Menschenjagd und Massendeportation von Arbeitskräften nach dem Osten « innerhalb der besetzten Länder ${ }^{470}$ und die >Austilgung des Judentums ${ }^{471} \mathrm{zu}$ sprechen. Kurz vor dem Ende des Zweiten Weltkrieges veröffentlichte er den Artikel Hitler und sein Reich, in dem er auch und vor allem die nationalsozialistische Terrorpolitik nach dem Reichstagsbrand am 27. Februar 1933 (auch mit Blick auf die sogenannte Schutzhaft und die Errichtung der ersten Konzentrationslager) und die Unterstützung der "Hitlerbewegung « durch die konservative Elite in den Kreisen der Wirtschaft, des Staates und der Wehrmacht thematisierte. ${ }^{42}$ Darüber hinaus untersuchte er nach dem alliierten Sieg gegen Deutschland die geistige und politische Topografie in der sich herauskristallisierenden bipolaren Weltordnung. ${ }^{473}$

Neben diversen Artikeln zur Geschichte, zur internationalen Politik und einer Veröffentlichung zu de Montaigne ${ }^{474}$ stand bei Lüthy im Monat auch die kritische Auseinandersetzung mit den Themen Europa ${ }^{475}$ Nationalismus, ${ }^{476}$ Intellektuelle, ${ }^{477}$ Nationalsozialismus ${ }^{478}$ sowie (Sowjet-)Kommunismus ${ }^{479}$ - einschließlich der (vergleichbaren)

teste u. a. der französischen Kirche (siehe ebd., S. 25). Zu den Implikationen der Judenverfolgung und -deportation schrieb Lüthy am 19. September 1942: „Wer die Freiheit und Menschenwürde einer Minderheit preisgibt, gibt seine eigene Freiheit und Menschenwürde preis. Vor wenigen Wochen wurden >nur die Juden< aus »Vichy-Frankreich deportiert; nun droht jedem Franzosen von siebzehn bis fünfzig, jeder Französin von einundzwanzig bis fünfunddreißig Jahren die Deportation.« (Ebd., S. 28)

468 Ebd., S. 227.

469 Ebd., S. 291.

470 Ebd., S. 185.

471 Ebd., S. 37.

472 Siehe ders., Adolf Hitler †, in: Ders., Nach dem Untergang des Abendlandes. Zeitkritische Essays, Köln 1964, S. 17-24.

473 Siehe grundsätzlich ders., Bis zur Neige. Epilog des zweiten Weltkrieges 1944/45, St. Gallen 1945. Aus diesem Buch erschienen als Fragmente: »Die Verheerungen des Krieges« in: Ders., Nach dem Untergang des Abendlandes. Zeitkritische Essays, S. 50-79, sowie »Der Friede, der keiner war«, in: Ebd., S. 80-101. Siehe zudem ders., Fragmente zu einem Instrumentarium des geistigen Terrors, in: Ebd., S. $25-49$.

474 Montaigne oder die Wahrhaftigkeit, in: Der Monat 5 (1953), H. 54, S. 599-615 (Einführung zu der Veröffentlichung: Aus den »Essais«, in: Ebd., S. 615-628 [einer Auswahl von Texten aus dem Buch: Michel de Montaigne, Essais. Auswahl und Übersetzung von Herbert Lüthy, Zürich 1953]).

475 Siehe exemplarisch: Wirtschaftseinheit-oder was sonst?, in: Der Monat 5 (1953), H. 55, S. $26-44$.

476 Rehabilitation des Nationalismus, in: Der Monat 12 (1960), H. 141, S. 5-13.

477 Siehe bes.: Vom armen Bert Brecht, in: Der Monat 4 (1952), H. 44, S. 115-144; Der Theologe unterm Schachbrett. Über den Schriftsteller Walter Benjamin, in: Der Monat 8 (1956), H. 93, S. 67-72, sowie Rivarols ]ünger-oder ]üngers Rivarol?, in: Der Monat 9 (1957), H. 101, S. 56-70.

478 Der Führer persönlich. Gedanken beim Lesen zweier Biographien, in: Der Monat 6 (1953), H. 62, S. 149-161 (Sammelrezension). Auf den Rezensionsaufsatz gehe ich in Kap. IV.1 ein.

479 Siehe bes. die Veröffentlichungen im Kontext des »Rousset-Prozesses«: Herbert Lüthy, David Rousset contra »Lettres Françaises«. Ein großer Prozeß vor einem kleinen Tribunal, in: Der Monat 3 (1951), H. 28, S. 349-354, sowie Brief aus Paris: David Roussets »]e propose ...«. Die Untersuchung der Ver- 
Verbrechensdimensionen der beiden totalitären Herrschaftssysteme ${ }^{480}$ - im Vordergrund. Gleichwohl rückten in erster Linie die innen- und außenpolitischen Zustände Frankreichs in das Zentrum seiner Beiträge. ${ }^{481}$ In diesem Zusammenhang beschäftigte er sich in seinen kritischen Untersuchungen mit der Regierungspolitik, ${ }^{482}$ der französischen Kolonialpolitik, ${ }^{483}$ der rechtsradikalen Bewegung von Pierre Poujade ${ }^{484}$ und insbesondere mit der politischen Linken sowie ihren einflussreichen französischen Intellektuellen - wie beispielsweise Jean-Paul Sartre. ${ }^{485}$

\section{Warum hat Franz Neumann nicht im Monat geschrieben? Ein >Negativporträts}

Im Anschluss an die Porträts von den zehn Autoren des Monat soll in diesem »Negativporträt« versucht werden, eine Antwort darauf zu finden, warum der renommierte NS-Forscher Franz Neumann nicht im Monat geschrieben hat, obwohl er im Laufe der Jahre bis zu seinem Tod im Jahre 1954 prädestiniert gewesen wäre, in der Zeitschrift $\mathrm{zu}$ publizieren. Abgesehen von der persönlichen Lebensgeschichte von Neumann ist damit besonders folgender Sachverhalt gemeint: erstens die wissenschaftlichen Veröffentlichungen, die im Grunde genommen von Anfang an den Totalitarismus als Herrschaftsregime in den Blick nahmen und in denen nach Kriegsende aus einer analytischen Perspektive heraus ein expliziter und impliziter Vergleich zwischen

schlepptenlager durch Verschleppte, in: Der Monat 2 (1950), H. 16, S. 353-356; Vgl. hierzu auch das Kap. III.

480 Obwohl Lüthy sich mit den totalitären Herrschaftssystemen des Nationalsozialismus und des Sowjetkommunismus auch in vergleichender Perspektive auseinandersetzte, war er gleichwohl kein »Anhänger« der klassischen Totalitarismustheorie, weil sie ihm nicht als geeignetes Instrument erschien, die spezifischen Besonderheiten der beiden Regime auf den Begriff zu bringen. Die Veröffentlichungen beispielsweise der ihm persönlich bekannten Theoretiker Hans Kohn und Hannah Arendt wurden von ihm in den 1940- bzw. 1950er-Jahren auch nicht rezipiert. Mitteilung von Lüthy in einem Gespräch mit dem Verfasser in Basel im Juli 2001.

481 Siehe grundsätzlich: Die Vierte Republik. Von Charles de Gaulle zu Henri Queuille, in: Der Monat 1 (1949), H. 8/9, S. 120-134, sowie Die Vierte Republik. Frankreich seit seiner Befreiung, in: Der Monat 1 (1949), H. 10, S. 39-48. Vgl. hierzu Herbert Lüthy, Frankreichs Uhren gehen anders, Zürich u. a. 1954; das Buch entstand aus den beiden zuerst im Monat publizierten »kritischen Essays«. Siehe auch: Vier Jahre später. Frankreichs Uhren gehen immer noch anders, in: Der Monat 10 (1958), H. 114, S. 33-43 (hierbei handelte es sich um das Nachwort der Neuauflage des Buches, das im selben Jahr erschien).

482 Siehe bes. Brief aus Paris: Stabilität oder Stagnation. Die innenpolitische Situation Frankreichs, in: Der Monat 3 (1951), H. 35, S. 465-476; Brief aus Paris: Mendes-France als Liquidator. Frankreichs Rückkehr zur »Realpolitik«, in: Der Monat 7 (1954), H. 73, S. 4-14, sowie Brief aus Paris: Frankreich persönlich? Zu den Memoiren des General Charles de Gaulle, in: Der Monat 9 (1956), H. 98, S. 11-22.

483 Siehe bes.: Das überseeische Frankreich. Ein Kolonialreich in der Krise, in: Der Monat 2 (1949), H. 14, S. 175-186; Brief aus Tunis: Nordafrika wird mündig, in: Der Monat 4 (1952), H. 47, S. 498-515; Ruhm und Ende der Kolonisation, in: Der Monat 9 (1957), H. 106, S. 26-39, sowie Frankreichs Hauptstadt: Algier. Algerien desintegriert das Mutterland, in: Der Monat 10 (1958), H. 118, S. 22-35.

484 Siehe Aufstand in der Wüste. Pierre Poujade und seine »Bewegung«, in: Der Monat 7 (1955), H. 80 , S. 119-127, sowie Heil Poujadolf?, in: Der Monat 8 (1956), H. 90, S. 3-12.

485 Siehe bes. Brief aus Paris: Frankreichs heimatlose Linke, in: Der Monat 2 (1950), H. 19, S. 8-17, sowie Jean-Paul Sartre und das Nichts, in: Der Monat 7 (1955), H. 83, S. 407-414. Vgl. hierzu auch das Kap. III. 